\section{General Medical Council report exposes unethical recruitment of doctors in the UK from low-resource countries}

To the Editor: The recent 'The state of medical education and practice in the UK 2020' report from the General Medical Council (GMC) ${ }^{[1]}$ reveals that in 2019 , doctors who obtained their medical qualification overseas comprised nearly $35 \%$ (86 794/251 319) of all those licensed to practise in the UK, and that between July 2019 and June 2020 a further 10000 such doctors registered - many more than those who registered with a qualification from the UK.

The UK already has one of the highest proportions and overall numbers of overseas-qualified doctors in its workforce, ${ }^{[2]}$ yet continues to actively encourage and support overseas health workers to relocate. Current UK immigration rules ${ }^{[3]}$ recognise all medical practitioners (as well as nurses, paramedics, radiographers, occupational therapists, and speech and language therapists) as shortage occupations, and for migrants offered such a post in the National Health Service (NHS) grant a reduced visa fee and support with relocation.

In their strategy for the future, the $\mathrm{GMC}^{[1]}$ suggested that 'overall numbers will need to rise further ... likely to require a continuation of the large number of doctors from overseas joining our workforce'. This position seems insensitive to the well-documented and morally questionable problem of 'brain drain. ${ }^{[4]}$ A report by the World Health Organization in $2006^{[2]}$ found that on average a quarter of doctors in sub-Saharan Africa had migrated to work in highincome countries, and yet we know that only $5 \%$ of people in subSaharan Africa have access to timely, safe and affordable surgery. ${ }^{[5]}$ Of doctors recently registered by the GMC, the largest number was from South Asia, ${ }^{[1]}$ and yet in South Asia only $3 \%$ of patients have access to surgery. ${ }^{[5]}$ Saluja et al. ${ }^{[6]}$ reported that the movement of physicians from lower- to higher-income settings has substantial economic consequences that are not simply due to movement of human capital, but also due to excess mortality associated with loss of physicians.

We have previously expressed concern that as the COVID-19 pandemic makes health workforce shortages in countries such as the UK and USA more apparent, migrant workers should not be used to fill the gap. ${ }^{[7]}$ However, in March 2020, the GMC expedited registration of many migrant doctors to help the NHS response to the pandemic. ${ }^{[1]}$ As low- and middle-income countries battle COVID19 on top of a fragile health infrastructure, they need their medical workforce to stay home.

When politicians and healthcare planners err by not training enough of their own healthcare personnel to care for their population, or do not create working conditions to retain staff, then they should pay the price, not patients and health systems in poorerresourced countries. The UK government, the NHS and the GMC need to reconsider their recruitment drive of overseas medical personnel, especially from low- and middle-income nations. It is simply unethical to do so.

\section{Johannes J Fagan}

Professor and Chairman, Division of Otolaryngology, Faculty of Health Sciences, University of Cape Town, South Africa

johannes.fagan@uct.ac.za

\section{Mahmood F Bhutta}

Consultant and Honorary Clinical Professor, Department of ENT

Surgery, Royal Sussex County Hospital, Brighton, UK

1. General Medical Council. The state of medical education and practice in the UK 2020. https://www. gmc-uk.org//media/documents/somep-2020_pdf-84684244.pdf?la=en\&hash=F68243A899E21859A B1D31866CC54A0119E60291 (accessed 29 November 2020).

2. World Health Organization. World Health Report: Working together for health, 2006. http://www who.int/whr/2006/whr06_en.pdf (accessed 29 November 2020).

3. Home Office, UK. Immigration Rules Appendix Shortage Occupation List. https://www.gov.uk/guidance/ immigration-rules/immigration-rules-appendix-shortage-occupation-list (accessed 29 November 2020). Shahvisi A. Health worker migration and migrant healthcare: Seeking cosmopolitanism in the NHS Bioethics 2018;32(6):334-342. https://doi.org/10.1111/bioe.12432

Alkire BC, Raykar NP, Shrime MG, et al. Global access to surgical care: A modelling study. Lancet Glob Health 2015;3(6):e316-e323. https://doi.org/10.1016/S2214-109X(15)70115-4

6. Saluja S, Rudolfson N, Massenburg BB, Meara JG, Shrime MG. The impact of physician migration on mortality in low and middle-income countries: An economic modelling study. BMJ Glob Health 2020;5(1):e001535. https://doi.org/10.1136\%2Fbmigh-2019-001535

7. Fagan JJ, Cairncross L, Biccard B, Fieggen G, Maswime S. COVID-19 exposes health worker shortages . Fagan J), Cairncross L, Biccard B, Fieggen G, Maswime S. COVID-19 exposes health worker shortages
in the USA and UK, but nationalism and self-interest must not exploit medical workforces from in the USA and UK, but nationalism and self-interest must not exploit medical workforces from
low- and middle-income countries. S Afr Med J 2020;110(5):335. https://doi.org/10.7196/SAMJ.2020. v110i5.14774

S Afr Med J 2021;111(3):189. https://doi.org/10.7196/SAMJ.2021.v111i3.15479 